\title{
Accidents With Biological Material Among Undergraduate Nursing Students in a Public Brazilian University
}

\author{
Renata Karina Reis, Elucir Gir \\ and Silvia Rita M. S. Canini
}

\author{
Department of General and Specialized Nursing of the \\ University of São Paulo at Ribeirão Preto College of \\ Nursing, Ribeirão Preto, SP, Brazil
}

\begin{abstract}
During their academic activities, undergraduate nursing students are exposed to contamination by bloodborne pathogens, as well as by others found in body fluids, among which are the Human Immunodeficiency (HIV), Hepatitis B and C viruses. We developed a profile of victimized students, characterizing accidents with biological material occurring among undergraduate nursing students at a public university in São Paulo State, Brazil. We identified the main causes and evaluated the conduct adopted by students and their reactions and thoughts concerning the accidents. Seventy-two accidents were identified, of which $17 \%$ involved potentially contaminated biological material. Needles were the predominant cause of accidents. The most frequently involved topographic areas were the fingers. Only five students reported the accidents and sought medical care. Among these, two students were advised to begin prophylactic treatment against HIV infection by means of antiretroviral drugs. It was found that the risk of accidents is underestimated and that strategies such as formal teaching and continual training are necessary in order to make students aware of biosafety measures.
\end{abstract}

Key Words: Undergraduate students, occupational accident, biosafety.

Exposure to biological agents is the most common occupational risk for health professionals. When compared to other health personnel, the nursing staff is the group that is most frequently victimized by accidents with cutting and piercing objects, since these professionals are also the ones who most often handle such materials while performing their tasks [1-3].

Occupational accidents, particularly those involving cutting and piercing instruments among health professionals, have been a cause for increasing concern due to the prevalence of diseases and infections caused by the Human Immunodeficiency (HIV), Hepatitis B and $\mathrm{C}$ viruses, which are sometimes asymptomatic and

Received on 07 September 2003; revised 07 January 2004. Address for correspondence: Dr.Elucir Gir. Av. Bandeirantes, 3900 - Campus Universitário-University of São Paulo at Ribeirão Preto College of Nursing, Ribeirão Preto,SP, Brazil. Zip code: 14040-902.E-mail: egir@urp.usp.br

The Brazilian Journal of Infectious Diseases 2004;8(1):18-24 (C) 2004 by The Brazilian Journal of Infectious Diseases and Contexto Publishing. All rights reserved. unnoticed, thus increasing the possibility of contamination.

Gir et al. [2] reported that before the advent of HIV, accidents involving cutting and piercing objects were underestimated, although the risk of contamination by bloodborne pathogens, among which are the Hepatitis$B$ and $C$ viruses, were well-known.

Though they have technical/scientific training, undergraduate nursing students develop their skills needed for patient care by handling cutting and piercing objects as well as body fluids, thus they are frequently exposed to biological risks. The students spend different periods of time at various training sites, during which they develop a variety of teaching-learning activities. Lack of experience and anxiety can contribute to the occurrence of accidents. Furthermore, undergraduate students are undergoing learning, supervision and evaluation situations and these factors can also increase stress and anxiety.

Therefore, undergraduate education must promote students' sensibilization, from the beginning to the 
completion of their program, concerning the need to apply measures aimed at the reduction of occupational risks, with emphasis on the utilization of the so-called standard precautions. Such procedures must be adopted by health professionals for all patients, regardless of their diagnosis, and they must be applied whenever exposure to blood and other body fluids may occur, whether or not the blood, injured skin and mucous membranes are visible. Suchmeasures include hand washing, the use of individual protective equipment (IPE) and care when handling and disposing of cutting and piercing objects [4].

Therefore, in order for effective behavioral changes to occur, based on sensibilization concerning this problem, the development of an individual and group sense of responsibility must be developed. Education is the best way to prevent contamination by pathogens found in blood and other body fluids; it must be associated with the use of individual protection equipment and vaccines in addition to the development of new work techniques and equipment aiming at workers' protection [5]. We agree that "having access to information does not necessarily mean being aware, being aware does not necessarily mean taking measures and taking measures does not necessarily mean doing" [6]. In order to evaluate education/knowledge concerning the prevention of accidents involving blood and other body fluids aiming at adopting adequate measures, knowledge regarding the students' profiles and the circumstances under which such accidents take place is necessary.

Considering undergraduate nursing student as a future health professional, and in view of the magnitude of the problem presented, knowledge concerning biosafety becomes essential so that they can develop self-protecting prevention measures. Consequently, this investigation aimed at characterizing accidents involving biological material among undergraduate nursing students in a public Brazilian university in São Paulo state, Brazil. Its goals were: to identify the types of accidents occurring; to identify the topographic areas affected; to identify the major causes attributed by the people victimized; to evaluate the conduct adopted in view of the accident as well as the reactions generated by the accident.

\section{Material and Methods}

\section{Population and sample}

The population of the study consisted of 124 students regularly enrolled in the $3^{\text {rd }}$ and $4^{\text {th }}$ years of the undergraduate nursing program at a public university in São Paulo state, Brazil, in 2001.

The sample was composed of 50 students who reported to have been victimized by accidents caused by cutting and piercing objects or had mucouscutaneous exposure during their nursing activities in hospitals or Basic Health Units and who agreed to participate in this investigation by signing an informed consent form (Appendix 1).

\section{Data collection}

A guided form containing open and closed questions was designed and used for data collection (Appendix 2 ). By means of semi-structured interviews, the questionnaire was applied to undergraduate nursing students. Any occurrences involving cutting or piercing objects or contact with biological materials (blood, liquor, feces, amniotic fluid, pericardial fluid or pleural fluid) with injured skin or mucosa which occurred during curricular training were considered to be accidents.

\section{Ethical aspects}

This study was evaluated and approved by the Committee of Ethics in Research of the University of São Paulo at the Ribeirão Preto College of Nursing.

\section{Results}

Of the 124 undergraduate nursing students regularly enrolled in the $3^{\text {rd }}$ and $4^{\text {th }}$ years, $50(40 \%)$ reported to have been victimized by some type of accident with cutting and piercing objects or had contact of biological material with their skin or mucosa (Table 1).

Concerning gender, it was found that most of the students, that is $96 \%$, were females, which denotes a 


\section{Appendix 1}

\section{Informed Consent Form}

I hereby declare that I am aware of the objectives of the study entitled Accidents with biological material among undergraduate nursing students in a public Brazilian university and I agree to participate in it as a subject and, therefore, to answer the questions comprising the interview. I am aware of the fact that secrecy and anonymity concerning the informer's identification and his affiliations will be ensured and that this investigation will not cause me any harm or exposure.

Ribeirão Preto

ID no.

\section{Appendix 2}

\section{Data Collection Instrument}

1. Gender: male ( ) female ( )

2-. Age:_ years old

3. Student in the: $2^{\text {nd }}() 3^{\text {rd }}() 4^{\text {th }}($ ) year of the undergraduate program

4. How many accidents have you had? 1( ) 2( ) 3( ) 4( )

5. Object causing the accident:
( ) piercing
( ) others
( ) cutting

5.1- Material/secretion:
( ) blood sprinkle
( ) secretion sprinkle

5.2 ( ) potentially contaminated ( ) non-contaminated

6. Topography affected:

7. Was suture necessary?

8. What course were doing?

9. What activity were you developing when the accident occurred?

10. Did the procedure performed require the use of an IPE?

Yes ( ) No ( ) Which:

11. What cause do you attribute to the accident?

12. What were the conducts adopted in view of the accident?

13. Was your vaccination scheme against Hepatitis B complete at the time of the accident? Yes ( ) No( ) Why/Why not?

14. What did you feel as a result of the accident?

15. Did you seek medical care? Yes ( ) No ( ) It does not apply ( )

Where?

How long after the accident? 
characteristic of the nursing profession, since it is predominantly constituted by females. An examination of the age range of the victimized students indicated that $68 \%$ were 20 to 22 years old.

Table 1. Distribution of victimized students according to class status, Brazil, 2001

\begin{tabular}{lcc}
\hline Programyear & $\begin{array}{c}\text { No.of victimized students } \\
\text { N }\end{array}$ & $\begin{array}{c}\text { Total } \\
\mathbf{\%}\end{array}$ \\
\hline $3^{\text {rd }}$ year & 13 & 26 \\
$4^{\text {th }}$ year & 37 & 74 \\
Total & $\mathbf{5 0}$ & $\mathbf{1 0 0}$ \\
\hline
\end{tabular}

Among the 50 victimized students, $62 \%$ reported the occurrence of only one accident, $38 \%$ reported two, and $6 \%$ reported three, which totalized 72 accidents, thus indicating that students are commonly exposed to this type of accident.

In the examination of the type of object/material causing the event, it was found that $51 \%$ were caused by piercing objects, $44 \%$ by cutting objects and $4 \%$ by spray into the eye mucosa (Table 2 ).

In $83 \%$ of the incidents, there was no exposure to body fluids, since the object had not been used on the patient. Of these, $48 \%$ were caused by piercing objects and $52 \%$ by cutting objects; however, despite the fact that they were not contaminated, the natural skin barrier was broken, thus allowing for the penetration of pathogens if contact with biological material occurred on this area.
Among piercing instruments, the predominant objects causing accidents were needles, which were also responsible for most of the accidents with potentially contaminated material. Among cutting objects (ampoules, scissors, glass vials), accidents involving medication vials-ampoules were the most frequent.

Of the 72 accidents reported, it was found that $17 \%$ had occurred with potentially contaminated material.

The risk of HIV contamination by means of percutaneous accidents with contaminated blood is estimated to range from $0.3 \%$ to $0.4 \%$, and to be $0.09 \%$ for muco-cutaneous events [7]. This means that of every 250 to 300 punctures, one presents risk of serum positivity for HIV [8]. The risk of infection by Hepatitis-B virus (HBV) ranges from 6\% to $30 \%$, if no prophylactic measure is adopted; however, a combination of vaccines and gamma globulin can reduce this risk $90 \%$ to $95 \%$ [9].

Accidents with potentially contaminated biological material must be treated as medical emergency cases, given that prophylactic interventions against infection by HIV and the Hepatitis-B virus are more effective if they are initiated immediately after the accident [10]. However, prophylactic measures following exposure are not completely efficient, which makes permanent educational actions necessary, mainly aiming at accident prevention.

Therapeutic alternatives presently available do not offer total efficacy in the reduction of transmission risks

Table 2. Distribution of accidents in nursing students, according to the object/material causing it.

\begin{tabular}{lcccccc}
\hline \multirow{2}{*}{ Material/object } & \multicolumn{2}{c}{ Non-contaminated } & \multicolumn{3}{c}{ Potentially contaminated } & \multicolumn{2}{c}{ Contaminated } \\
& $\mathbf{N}$ & $\mathbf{\%}$ & $\mathbf{N}$ & $\mathbf{\%}$ & $\mathbf{N}$ & $\mathbf{\%}$ \\
\hline Piercing & 29 & 78.4 & 8 & 21.6 & 37 & 100 \\
Cutting & 31 & 96.9 & 1 & 3.1 & 32 & 100 \\
Blood/secretion sprinkle & - & - & 3 & 100 & 3 & 100 \\
Total & $\mathbf{6 0}$ & $\mathbf{8 3 . 3}$ & $\mathbf{1 2}$ & $\mathbf{1 6 . 7}$ & $\mathbf{7 2}$ & $\mathbf{1 0 0}$ \\
\hline
\end{tabular}


following occupational exposure to Hepatitis-C virus (HCV). The average infection risk after a percutaneous accident is $1.8 \%$; it ranges from 1 to $10 \%,[7]$ and the possibility of complications during the development of the disease is 4 to 10 times higher than that for HBV [10].

When comparing risk values of HIV with those of $\mathrm{HBV}$ and $\mathrm{HCV}$, it is observed that the values for HIV are considerably smaller; however, there is evidence that occupational exposure to blood and other body fluids occurs quite frequently in hospitals [8]. Occupational infection has been thoroughly documented [11].

When questioned about the reporting of accidents involving potentially contaminated biological material, 7 of the 12 students informed that they had not sought medical care or reported the accident, 5 sought medical care and reported the occupational accident, 2 of whom used prophylactic antiretroviral therapy for HIV.

In addition to the underestimation of infection risks due to occupational exposure, the period of time following the accident until seeking medical care ranged from 20 minutes to 4 hours. It is known that when indicated, chemoprophylaxis must be initiated as soon as possible, ideally within 1 to 2 hours following the accident [7].

The indication to use antiretroviral medication must be based on a detailed evaluation of the risk of HIV transmission, which includes the depth of the lesion caused by the piercing or cutting instrument, presence and amount of visible blood on the object causing the accident, previous use of the object in the patient's vein or artery, caliber of the instrument causing the accident as well as the source patient's level of HIV infection [10].

Among the 50 students reporting accidents, 48 had been completely vaccinated against Hepatitis B at the time of the accident while the other 2 had not.

Vaccination against Hepatitis B is confirmedly effective, and presents a vaccinal response ranging from 90 to $95 \%$ in immunocompetent adults. A series of three doses applied intramuscularly in the deltoid region is recommended. The second dose must be administered one month after the first dose, followed by the third dose six months after the first [7]. Vaccination is recommended to all health professionals and students, since the risks of infection by HBV to which such professionals are exposed have been well documented and vaccine adherence has led to a considerable reduction in this risk, although some professionals are reluctant to its use and fail to complete the vaccination scheme [5].

The most frequently affected body region in the accidents was the fingers (Table 3). Various studies on occupational accidents have shown that upper limbs are more frequently affected, particularly hands and fingers $[1,3,5,12]$.

Table 3. Distribution of accidents among undergraduate students according to the topographic area, Brazil, 2001

\begin{tabular}{lrr}
\hline Topographic area & $\mathbf{N}$ & \% \\
\hline Fingers & 65 & 90.2 \\
Hand palms & 3 & 4.2 \\
Eye (mucosa) & 3 & 4.2 \\
Leg & 1 & 1.4 \\
Total & $\mathbf{7 2}$ & $\mathbf{1 0 0}$ \\
\hline
\end{tabular}

Among the causes attributed by the students, it was observed that most were related to professional inexperience, and technical inability as well as to the difficulty in handling cutting and piercing material (Table 4). Lack of attention was also indicated as one of the causes of the accidents, which shows the students' need for continual training, aiming at developing better technical abilities in order to reduce the frequency of accidents.

When he analyzed accidents involving biological materials among the nursing staff of a teaching hospital in São Paulo state, Canini [1] found that most of the professionals who were victims had been working for less than a year at the time of the accident and she pointed out that professional inexperience and inability to handle cutting and piercing materials increases the risk of accidents. 
Table 4. Distribution of the cause attributed to each accident as reported by undergraduate nursing students

\begin{tabular}{lrr}
\hline Attributed causes & N & \% \\
\hline Lack of attention/distraction & 16 & 22.2 \\
Inexperience & 10 & 13.9 \\
Inadequate technique & 7 & 9.7 \\
Technical inability & 5 & 6.9 \\
Insecurity/nervousness & 5 & 6.9 \\
Difficulty to handle the material & 5 & 6.9 \\
Hurry & 5 & 6.9 \\
Unavoidable & 4 & 5.5 \\
Carelessness & 4 & 5.5 \\
Pressure by the patient & 3 & 4.2 \\
Needle recapping & 3 & 4.2 \\
Neglect by a colleague & 2 & 2.8 \\
Lack of material & 2 & 2.8 \\
Imprudence & 1 & 1.4 \\
Total & $\mathbf{7 2}$ & $\mathbf{1 0 0}$ \\
\hline
\end{tabular}

Other important factors to be considered in relation to the accidents among students are the insecurity, nervousness and anxiety generated when their activities with patients begin.

It has also been noted that inadequate conduct by the students, such as needle recapping, as well as inadequate performance of techniques, contributed to the occurrence of accidents. Inadequate behaviors were also reported, such as hurry and pressure by the patient. Among the measures adopted after the accident, different courses of action were identified according to the type of exposure. Forty-two (59\%) indicated adequate procedures, such as hand washing and the application of dressings on injuries caused by cutting, thus preventing contamination by microorganisms; 3 washed their eyes with water when a secretion was sprayed or splattered onto eye mucosa; however, 8 reported no corrective action, and non-recommended behaviors, such as "squeezing" the accident site, were also reported.

The conduct adopted after accidents depends on the type of object/material causing it. Washing the lesion with water, soap and anti-septic solutions is recommended, whereas the use of caustic substances such as sodium hypochlorite is contraindicated. Additionally, the injured site should not be expressed (squeezed), as this can increase the affected area as well as the exposure to the contaminating material [10]. In case of exposure of the mucosa, it must be immediately and exhaustedly washed with water or physiological serum, and the use of topical antiviral medication is indicated in situations of contact with material infected by Herpes Simplex [10].

Caring for the affected site is fundamental; however, it is not the only measure to be adopted. It was observed that among the 12 students reporting percutaneous accidents with biological material, only 5 sought medical care. Washing the site with soap and water and antiseptic solution such as $70 \%$ alcohol or products made from iodine is recommended whenever the skin is exposed to biological material. In case the mucosa is exposed, washing immediately and exhaustedly with water or physiological serum is recommended [8].

In spite of the fact that $83 \%$ of the accidents did not involve exposure to biological material, the students reported negative feelings such as anger, insecurity, concern, and fear, as well as low self-esteem feelings such as frustration, incapacity and incompetence. Many of themreported that they feared infection, especially by HIV.

The need to involve students with the topic of biosafety is pointed out in order to educate future nurses who will be conscious of their professional practice, thus providing a safe work environment for health professionals as well as for patients. Among its other goals, biosafety aims at the prevention of accidents in the work environment; therefore, it is highly relevant that it should be addressed during the education of health professionals in general, and nursing undergraduates in particular, as they are frequently and directly in contact with blood and other body fluids while handling cutting and piercing objects, thus exposing themselves to occupational risks.

\section{Discussion}

Our findings enabled us to identify accidents with cutting and piercing instruments, exposure to biological materials and the underlying causes attributed by undergraduate nursing students. 
Twelve accidents (out of 72 incidents) with potentially contaminated biological material were identified, of which 8 were caused by piercing objects, 1 by a cutting object and 3 by fluid sprinkled onto the mucosa. Among these 12, only 5 sought medical care and reported the accident, thus disconsidering the risk of contamination by various bloodborne pathogens or by those found in secretions. Prophylaxis with antiretroviral medication against HIV contamination was indicated and implement by only 2 of the students.

The fingers were the most frequently affected anatomical region of the body. The two major causes attributed to the accidents were professional inexperience and distraction, which were regarded as contributing factors to the occurrence of accidents. Various feelings were awakened as a result of the accident and fear of contamination was the most frequently reported.

These undergraduate nursing students had direct and frequent contact with body fluids and cutting and piercing objects; therefore, the adoption of biosafety measures aiming at their protection is necessary. Considering undergraduate students as future health professionals, we emphasize the need to address biosafety, thus contributing to the education of nurses who will be conscious of their professional practice and providing a safe work environment for health professionals as well as their patients.

\section{References}

1. Canini S.R.M.S. Situações de risco para transmissão de patógenos veiculados pelo sangue entre a equipe de enfermagem de um hospital universitário do interior paulista. [Dissertação de Mestrado] Escola de Enfermagem de Ribeirão Preto da Universidade de São Paulo, 2000.

2. Gir E., Costa F.P.P, Silva A.M.A Enfermagem frente a acidentes de trabalho com material potencialmente contaminado na era do HIV. Rev Escola de Enfermagem da Universidade de São Paulo 1998;32(3):262-72.

3. Machado A.A., et al. Risco de infecção pelo vírus da imunodeficiência humana (HIV) em profissionais da saúde. Rev Saúde Pública 1992;26(1):54-6.
4. Garner J.S. Guideline for isolation precautions in hospitals. Infect. Control Hosp Epidemiol 1996; 17(1):54-80.

5. Basso M. Acidentes ocupacionais com sangue e outros fluidos corpóreos em profissionais de saúde. [Dissertação de Mestrado] Escola de Enfermagem da Universidade de São Paulo, 1999.

6. Gir E., Moriya T.M., Hayashida M., et al. Medidas preventivas contra a Aids e outras doenças sexualmente transmissíveis conhecidas por universitários da área da saúde. Rev Latino-americana de Enfermagem 1999;7(1):11-7.

7. Brasil, Ministério da Saúde. Secretária de Políticas de Saúde. Coordenação Nacional DST e Aids. Manual de condutas: Exposição Ocupacional a Material Biológica: hepatite e HIV, Brasília, 1999.

8. Brevidelli M.M. Exposição ocupacional ao vírus da AIDS e da Hepatite B: Análise da influência das crenças em saúde sobre a prática de reencapar agulhas, Dissertação de Mestrado, Escola de Enfermagem, São Paulo, 1997.

9. Centers For Disease Control. Guidelines for prevention of transmission of human immunodeficiency virus and hepatitis B virus to health care and public safety workers MMWR 1989;38(65):1-17.

10. Brasil, Ministério da Saúde. Secretaria de Estado da Saúde. Programa Estadual DST/AIDS-SP, Atualidades em DST/ AIDS. Biossegurança. São Paulo, junho, 1998.

11. Chamberland M.E., Ciesielski C.A, Howard R.J., et al. Occupational risk of infection with human immunodeficiency virus. Surgical Clin North Am 1995; 75(6): 1057-70.

12. Brandi S., Benati M.C.C., Alexandre N.M.C. Ocorrência de acidente do trabalho por material perfuro- cortante entre trabalhadores de Enfermagem de um Hospital Universitário de Campinas, Estado de São Paulo. Rev Escola de Enfermagem USP, 1998;32(2):124-33. 